\title{
How Can Strategic Leadership Support the 5 Functions of Strategic Management within University Environment?
}

\author{
MA'ALI M. AL-YOUSUFI \\ Kuwait University \\ KUWAIT
}

\begin{abstract}
Bearing in mind the highly important role that leadership has in modern business environment, and launching from the interconnected relationship between leadership and management; this research aimed at highlighting how strategic leadership can support strategic management function and in a university environment. Researcher adopted the five functions of strategic management which included (planning, organizing, staffing, leading and controlling). Through the adoption of quantitative approach and building a questionnaire to be the study tool; (137) individuals responded to an online uploaded questionnaire and SPSS was used in order to screen and analyzed collected primary data. Utilizing mean, standard deviation and linear regression, results indicated that characteristics of strategic leadership were able to support all functions of strategic management based on the common goals that both leadership and management had from a strategic perspective. Results of study accepted main hypothesis and agreed on the fact that strategic leadership supports functions of strategic management with an $\mathbf{R}$ value of $\mathbf{. 8 6 0}$ and a correlation coefficient of $\mathbf{7 4 \%}$. Concerning functions of strategic management which were mostly supported by strategic leadership; results indicated that staffing was the most positively influenced function of strategic management scoring an $\mathbf{R}$ value of $\mathbf{9 3 6}$ with a correlation coefficient of $\mathbf{8 7 . 6 \%}$. Study recommended that risk management in all its forms and strategies is the most important fact in this scheme, given that strategic management is mostly based on managing in an unpredictable environment that is unstable and risky. Practical contribution of current study can be summed in the fact that it could be a source for leaders to deeply understand what strategic leadership is and how it can help strategic management be applied correctly in an educational environment.
\end{abstract}

Key words:- Strategic Management, Strategic Leadership, Organizational Structure, Staff, Strategic Leader, Management Theories, Openness, Modern Business Environment

Received: May 28, 2021. Revised: January 21, 2022. Accepted: February 7, 2022. Published: February 25, 2022.

\section{Introduction}

An environment of chaos and disorganization is not a suitable environment for production and access to outputs that can deepen the productive impact of organizations and then advance the organization in terms of the products or services it provides, and therefore, it is the easiest and shortest way to lose the competitive advantage and get out of the market [25]. According to [6], management and then leadership came in order to organize the organizational environment and keep it away from chaos and disorganization as much as possible. With the passage of time, the leadership branched out with its methods, patterns and goals, some of which were in harmony with the qualities of the leader and some of them harmonized with the work environment, while other types of leadership came as a result of the organizational culture in which it was created [10].

Since the $80 \mathrm{~s}$ of $20^{\text {th }}$ century, organizations have been improving and developing their managerial and leadership positions by making efforts to reach a state of harmony and organization that includes their internal and external operations, their clients, their competitive environment and the working individuals [22]. [5] indicates that despite the great similarity between leadership and management, but each of them is separate from the other, provides different services and has specific characteristics different from the other, but the initial idea that appears to us today, that many scholars and academics proved that management preceded leadership, and that refining management skills and integrating them with individuals is the first stage in order to create meaningful leaders capable of achieving the required results [21].

\section{Problem Formulation}

Strategic leadership is one of the types of leaders that have proven effective in leading the organization and the individuals working in it based 
on the strategy adopted by higher management, and therefore it is the method or method in which the leader uses the organization's strategy in order to lead the team and work to motivate the team members and persuading them to achieve the goals of the organization based on convincing them of its strategy [11].

On the other hand, it indicates [14] that strategic leaders have the ability to contribute to improving the way the organization works by adopting effective strategies in team leadership, motivating individuals to work and employing the idea of strategic management well and fruitfully.

[9] emphasized that in strategic leadership, the strategic leader plays various roles aimed at leading the organizational environment first and then leading the change environment that may result from the application of the organization's strategies, where the leader formulates the organization's strategy and presents the vision to individuals clearly, and he evaluates For the strategy adopted based on a set of skills that would break the hierarchy within the internal operations of the organization, and thus, facilitate the activities of strategic management.

From that, current research sought to examine the approach in which strategic leadership has the ability to influence - in a positive way - strategic management within university environments.

\section{Literature Review}

\subsection{Leadership from a Strategic Perspective}

[16] Indicates in his study that strategic leadership represents the leader's ability to understand and assimilate the organization's strategy or part of it and to lead based on it by motivating working individuals to understand this strategy and try to achieve its goals and visions. Any strategic leader is someone who tries to manage employees based on and based on the organization's strategy [11].

As for [23] and [2], indicated that strategic leadership is the state in which the leader is able to manage change and deal with resistance to organizational change by spreading the spirit of motivation in working individuals and increasing their level of awareness and awareness of the organization's strategies and goals intended to be achieved through it, and this is done by the strategic leader drawing an organizational structure for the team, allocating resources to reach the goals, expressing the strategy and vision of the organization through his leadership and raising the team's ability to work in unstable and ambiguous environments.

On the other hand, [3] and [24] emphasized that strategic leadership in all its apparent and hidden meanings refers to (art), this art is based on the leader's ability to influence others in the interest of the organization, and the influence is through facilitating an understanding of the organization's strategy by individuals and digest them in the right way, and then convince them that achieving the objectives of the adopted strategy will be in their favor, this will influence their decisions and lead them to complete the work required of them in a smooth and correct manner, and thus achieve the desired with higher efficiency and less time.

\subsection{Who is the Strategic Leader?}

In order for the leader to be considered strategic, he must have many qualities, the most important of which is the ability to lead and work in an unstable and volatile environment, that is, the ability to complete projects and tasks assigned to the leader and his team despite the presence of obstacles, complications and events that would Impact on workflow, slowing it down, or even increasing its failure rate [11]. Here the strategic leader appears as one of the team that leads the rest of the individuals, motivates them towards reaching the goal, solves problems in a strategic and innovative way, and issues decisions that harmonize with the existing obstacles and thus achieve the desired, which is the success of the mission.

The strategic leader must also have problem-solving and decision-making skills based on their ability to analyze the factors in the surrounding environment, create alternatives in order to choose and adopt the most appropriate ones, and then apply these alternatives as a means to the success of the required task, then the strategic leader By evaluating the predetermined solutions and looking at the mechanism of their application and the extent of their success and impact on the process of completing the tasks [14].

[18] and [9] found that the strategic leader must have strong communication skills and a clear strategic vision that is easy to transfer to others. Subject since the strategic leader's work is based on long-term plans, and therefore he must be committed, passionate and patient.

[29] says that the strategic leader must be positive in dealing and the negativity does not interfere in the way they lead the team. Understand the feelings and feelings of individuals and have the ability to absorb the skills of individuals and deal with them individually. 
On the other hand, the strategic leader for [18] was the person with loyalty through words and deeds, as they are leaders who use force wisely, have a broad perspective and are not narrow-minded because they have a strong motivation based on their belief that achieving the interest of the organization will be to achieve the interest of their team in addition to their personal interest as individuals.

\subsection{Concept of Strategic Management}

It is normal that the organization cannot manage itself, but rather it needs administrative personnel who are able to draw general directions, define goals and policies, and then draw a road map in order to ensure that the organization reaches the desired goals [8]. Thus, the strategic management works on formulating, clarifying and achieving the goals of the organization based on the analysis of existing resources and the study of the internal and external environment of the organization.

By looking at the thousands of definitions of strategic management in the previous literature, it was possible to understand and comprehend the idea that strategic management is management based on two main pillars, the first is the management of resources and their allocation in a way that ensures the achievement of the goals of the organization, and the second is working in a volatile environment and unstable [20]. So it can be said that strategic management is the administrative process in which the senior management manages the resources of the organization based on the analysis of the organization's strategic goals, standing on its goals and objectives and analyzing the nature of the competitive environment in which the organization operates [12].

[7] and [8] presented another concept of strategic management, where he insisted that strategic management is an administrative process whose first and last objective is to manage the competitive environment in which the organization operates, and this is done through analyzing the competitive environment, identifying the capabilities of competitors, developing a competitive strategy that is capable of extending the life of the organization and hence, achieving goals regardless of the surrounding environment.

Moving from resource management to managing the competitive environment, [32] finds that strategic management is a managerial process based on coordinating the efforts of working individuals in order to achieve goals. Strategic management is the idea that the achievement of goals must be done depending on the resources available to the organization, whether they are administrative, technological, human, organizational, commercial or even natural resources.

\subsection{Strategic Management / Leadership within University Environment}

According to [26], leadership and strategic management are of great importance in the educational environment, as both terms are based on improving the level of resource management and raising the level of performance in a volatile environment. So, [30] and [28] argued that management, leadership and strategy have the ability to improve the level of polarization of individuals working in the academic environment considering they are human resources and therefore access to distinguished competencies and benefit from them.

The practice of leadership and strategic management in an educational environment contributes to increasing the interest and raising the level of organizational culture of the educational environment, leading to its consideration as positive and supportive of strategic planning, especially that leadership and strategic management are based on high communication and communication skills, information exchange and various reporting systems as was stated by [33]; [31] and [17]. It can be said that managing strategically and adopting strategic leadership in an academic environment contributes to managing the intellectual resources of the academic establishment, investing competencies in them, and achieving the required flexibility to deal with the volatile environment through the empowerment that is done strategically through training individuals (decision makers) to rationalize the use of their powers and thus support the elements of organizational performance [4].

\section{Hypotheses Development}

The idea of management in organizations regardless of its field of work - is based on bringing people together in order to achieve a common goal based on the available resources in an efficient and effective manner [1]. In the case of strategic management, the presence of strategic leadership makes the senior management an integral part of the team - with similar thought and ideology - and thus the gap between senior management and working individuals is reduced through the common link between them, which is strategic leadership, and strategic leadership comes with its thought Harmonious with strategic management by directing, organizing and motivating the team to 
work and achieve goals, which facilitates the process of strategic management and increases the chances of success of its tasks within the available resources and the unstable environment in which it operates.

Study by [15] aimed to determine the impact of strategic leadership on organizational performance and the relationship with senior management in Malaysian universities. And through the quantitative approach, responses were obtained from (135) leaders (dean) at the university, and the study reached the conclusion that strategic leadership has a direct impact on institutional performance, especially in educational environments, where strategic leadership contributes to understanding and assimilating goals It is hoped to be achieved by management, and strategic leadership comes in order to achieve distinct results for management functions in terms of planning, organizing, staffing, commanding and controlling. Thus, giving the individuals working in the team a thought and a cultural character similar to that of the senior management, this matter contributes greatly to pushing and motivating the team towards achieving the goals that the administration aspires to, because of the harmony between the senior management and the leadership that directs the team and his leadership.

In study by [13], it aimed to determine the impact of strategic leadership on competitive advantage by looking at the variables of strategic thinking and strategic planning. And based on the quantitative approach, (521) questionnaires were distributed to leaders working in 3 government hospitals in Jordan. The results of the study showed that although strategic thinking and planning are one of the functions of strategic management, the strategic leadership was able to transform this planning and strategic thinking into reality by leading and directing the work team in a strategic way that was adopted from the strategic plans that it set. Senior management, and therefore it can be said that strategic leadership was the strongest complement to strategic management, and to achieve the purpose of the study, the results proved that strategic leadership had an effective impact on the competitive advantage of organizations by persuading working individuals of the value and meaning of strategic goals, planning and hiring from in order to achieve them, and then draw up general policies and a roadmap for achieving these goals.

[14] in their study aimed to determine the impact of leadership on the formulation of the organization's strategic plan and the achievement of its objectives by reviewing the previous literature. The researcher pointed out that the organization is the body and strategic management is the soul, and therefore strategic leadership comes in order to link the soul and the body, and this is done by deepening the level of the team's understanding of the strategy adopted by the management in the organization and playing the role of the spiritual father of management from through the leader being the individual who links the team and the senior management, and thus the strategic management moves from being the brain that plans the organization's strategy to being part of the team and able to broadcast its ideas among individuals through leadership that carries the same ideological thought and is able to achieving goals.

Based on hypotheses development above, current study was able to formulate the following set of hypotheses:

\subsection{Main Hypothesis}

$\mathrm{H}$ : Strategic leadership supports functions of strategic management

\subsection{Sub-Hypotheses}

H1: Strategic leadership supports planning as a function of strategic management

$\mathrm{H} 2$ : Strategic leadership supports organizing as a function of strategic management

H3: Strategic leadership supports staffing as a function of strategic management

H4: Strategic leadership supports leading as a function of strategic management

H5: Strategic leadership supports controlling as a function of strategic management

Highlighting the relationship between variable in a more vivid way, researcher managed to build the following model: 


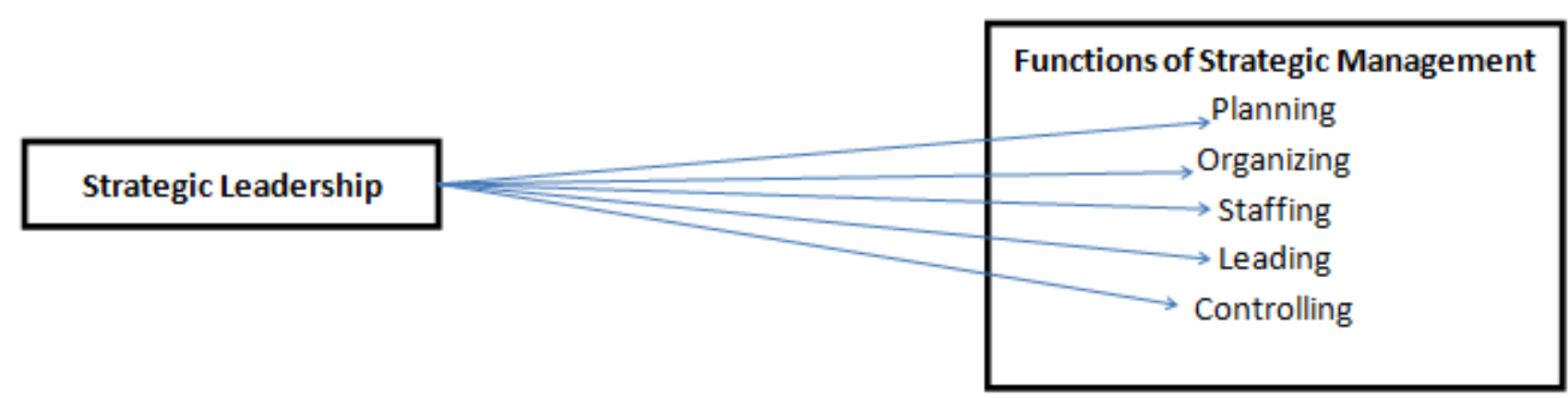

Fig. 1: Study Model ${ }^{[27 ; 14]}$

\section{Methods and Methodology}

Realizing aim of current research was done based on a group of methodological steps that paved the way for a smooth and academic goals achievement. Following section highlighted how this research was carried out.

\subsection{Method}

Quantitative approach was carried out due to its suitability - in recent circumstances-, researcher believed that qualitative approach was more suitable, but due to COVID 19 health precautions and the inability of researcher to meet with respondents and collect answers from them on open ended questions, the only choice was the quantitative approach as it preserve social distance and avoids the spread of the virus. It should be noted that the quantitative approach is based on positivist philosophy, which means that certain knowledge is based on familiarity with phenomena based on empirical facts available by empirical science.

\subsection{Tool of Study}

Questionnaire was chosen to represent the main tool of study, the questionnaire was built by researcher depending on previous literature, it was divided into two main sections, the first took into perspective demographics of respondents, while the other section presented statements that were related to study variables (planning, organizing, staffing, leading and controlling). Due to COVID 19 health precautions; the questionnaire was uploaded online through Google Forms, it remained online for total of 8 weeks. After that, researcher withdrew primary data on an excel sheet for purposes of screening and analysis.

\subsection{Population and Sampling}

Population of study consisted of all managerial or academic employees in Kuwaiti universities. A sample of (150) individuals were chosen to represent population of study. The questionnaire was uploaded online - due to COVID 19 health precautions - and after application researcher was able to retrieve (137) answered questionnaires which were valid for statistical analysis.

\subsection{Data Screening}

Data collected from questionnaires were tackled and processed depending on SPSS v. $27^{\text {th }}$. A group of statistical tests were used in order to facilitate aim achievement which included:

- Descriptive statistics (frequency, mean, standard deviation and percentages)

- Linear Regression

- Cronbach's alpha was used to test consistency of scale and $\alpha=0.906$ reflected that the scale was reliable since it was greater than accepted percent 0.60 .

\section{Analysis}

\subsection{Demographics}

Table 1. Descriptive Statistics of Demographics

Gender

\begin{tabular}{llrr|r}
\hline & & Frequency & \multicolumn{2}{c}{ Percent } \\
\hline Valid & Males & 98 & 71.5 \\
\cline { 2 - 5 } & Females & & 39 & 28.5 \\
\hline
\end{tabular}




\begin{tabular}{|c|c|c|c|}
\hline \multirow[t]{4}{*}{ Valid } & $25-30$ & 3 & 2.2 \\
\hline & $31-36$ & 75 & 54.7 \\
\hline & $37-42$ & 29 & 21.2 \\
\hline & +43 & 30 & 21.9 \\
\hline \multicolumn{4}{|c|}{ Educational Level } \\
\hline \multirow[t]{3}{*}{ Valid } & $\mathrm{BA}$ & 10 & 7.3 \\
\hline & MA & 50 & 36.5 \\
\hline & PHD & 77 & 56.2 \\
\hline \multicolumn{4}{|c|}{ Experience } \\
\hline \multirow[t]{5}{*}{ Valid } & Less than 3 years & 3 & 2.2 \\
\hline & $4-7$ & 79 & 57.7 \\
\hline & $8-11$ & 36 & 26.3 \\
\hline & +12 & 19 & 13.9 \\
\hline & Total & 137 & 100.0 \\
\hline
\end{tabular}

As it can be seen from table 1 above, respondents to questionnaire majorly were males who appeared to form $71.5 \%$ of total sample, who were within age range of $31-36$ years old $54.7 \%$. In addition to that, table 1 indicated that majority of respondents who answered the questionnaire held $\mathrm{PhD}$ degree or were candidates $56.2 \%$ with an experience in university managerial environment of 4-7 years $57.7 \%$.

\subsection{Questionnaire Analysis}

Table 2. Mean and Standard Deviation of Statements

\begin{tabular}{|c|c|c|}
\hline & Mean & Std. Deviation \\
\hline \multicolumn{3}{|c|}{ Strategic Leadership } \\
\hline $\begin{array}{l}\text { Strategic leadership has the ability to determine strategic } \\
\text { directions of an organization }\end{array}$ & 3.8905 & .92099 \\
\hline $\begin{array}{l}\text { A strategic leaders is able to establish a high level of balanced } \\
\text { organizational control }\end{array}$ & 3.7810 & .89702 \\
\hline $\begin{array}{l}\text { With strategic leaders, the resource portfolio of an } \\
\text { organization is smoothly managed }\end{array}$ & 4.0803 & .51533 \\
\hline $\begin{array}{l}\text { Strategic leadership is always capable to sustain well-built } \\
\text { organizational culture }\end{array}$ & 3.7518 & .95318 \\
\hline Strategic leaders are always effective problem solvers & 3.7299 & .98894 \\
\hline \multicolumn{3}{|c|}{ Functions of Strategic Management } \\
\hline \multicolumn{3}{|l|}{ Planning } \\
\hline $\begin{array}{l}\text { Goals and objectives must be wisely chosen in order to realize } \\
\text { the approach of their achievement }\end{array}$ & 3.4964 & .95582 \\
\hline Planning requires a decision maker & 3.4380 & 1.02082 \\
\hline There must be a set of alternatives in order to plan well & 3.3431 & 1.05327 \\
\hline Planning means previously set roadmap to achieve goals & 3.3869 & .92552 \\
\hline $\begin{array}{l}\text { To plan well, means to have a group of team members who } \\
\text { can act well together }\end{array}$ & 3.2920 & 1.14507 \\
\hline \multicolumn{3}{|l|}{ Organizing } \\
\hline $\begin{array}{l}\text { Roles of team members must be set previously in an } \\
\text { intentional approach according to their skills }\end{array}$ & 3.6350 & .93050 \\
\hline $\begin{array}{l}\text { Organizing needs an environment which is suitable for } \\
\text { individuals to at in it }\end{array}$ & 3.6715 & .96337 \\
\hline $\begin{array}{l}\text { Organizing must be based on a well-built organizational } \\
\text { structure in the environment }\end{array}$ & 3.3796 & 1.05113 \\
\hline $\begin{array}{l}\text { A strategic management must be able to locate and determine } \\
\text { people who can do the needed tasks }\end{array}$ & 3.4745 & 1.01518 \\
\hline Problem solving in a part of strategic management & 3.9781 & .85291 \\
\hline
\end{tabular}




\begin{tabular}{|c|c|c|}
\hline \multicolumn{3}{|l|}{ Staffing } \\
\hline Position must be filled and kept filled & 3.9051 & .93055 \\
\hline $\begin{array}{l}\text { Staff must be chosen in coordination with organizational } \\
\text { needs }\end{array}$ & 3.8029 & .91426 \\
\hline Bias isn't an option when it comes to staffing & 4.0803 & .51533 \\
\hline $\begin{array}{l}\text { Reaching a common goals mean to have a well-chosen staff of } \\
\text { people }\end{array}$ & 3.7591 & .95120 \\
\hline Staffing has to be aligned with organizational structure & 4.1533 & .52707 \\
\hline \multicolumn{3}{|l|}{ Leading } \\
\hline $\begin{array}{l}\text { Leading is based on choosing roles that team members have to } \\
\text { play }\end{array}$ & 3.8686 & .96114 \\
\hline $\begin{array}{l}\text { To lead means to have an individuals who has the ability to } \\
\text { coordinate in a synchronized way }\end{array}$ & 3.9270 & .94429 \\
\hline $\begin{array}{l}\text { Strategic management means to reconcile differences between } \\
\text { individuals to achieve a common cold }\end{array}$ & 3.8394 & .93332 \\
\hline $\begin{array}{l}\text { Strategic managers and leaders must be responsive to sudden } \\
\text { changes }\end{array}$ & 4.1095 & .53795 \\
\hline Ethics are a big part of strategically managing people & 3.8029 & .95363 \\
\hline \multicolumn{3}{|l|}{ Controlling } \\
\hline Controlling requires a good decision maker & 4.1825 & .54529 \\
\hline $\begin{array}{l}\text { In order to be in control, member behavior must be also } \\
\text { controlled }\end{array}$ & 3.9124 & .95851 \\
\hline All tasks of members must be coordinated with their tasks & 3.8394 & 1.06573 \\
\hline $\begin{array}{l}\text { Plans are set, but their milestones must be monitored and } \\
\text { controlled }\end{array}$ & 3.7591 & 1.04688 \\
\hline Controlling people means to control organizational outcomes & 4.0146 & .74740 \\
\hline
\end{tabular}
well, means to have a group of team members who

Mean and standard deviation of respondents' answers' were calculated in table 2 above. However, results appeared to be positive as all means were higher than mean of scale 3.00 which gave an indication that respondents had positive attitudes towards statements of questionnaire giving that all of their means were above 3.00. going deeper into details, it was found out that the highest mean scored 4.18/5.00 which was for the statement articulated "Controlling requires a good decision maker" compared to the lowest mean which scored 3.29/5.00 for the statement articulated "To plan can act well together" but both still positive as they were higher than mean of scale.

On a general look at results, following table 3 presented mean and standard deviation for variables of study. It was seen that all respondents answered in a positive way regarding variables in general as all means scored higher than mean of scale 3.00. However, controlling was the highest as it scored 3.94/5.00 while planning scored the lowest $3.39 / 5.00$.

Table 3. Mean and Standard Deviation of Variables Mean Std. Deviation

\begin{tabular}{|c|r|r|}
\hline Strategic Leadership & 3.8467 & .59025 \\
\hline Planning & $\mathbf{3 . 3 9 1 2}$ & .86632 \\
\hline Organizing & 3.6277 & .74169 \\
\hline Staffing & 3.9401 & .56639 \\
\hline Leading & 3.9095 & .65168 \\
\hline Controlling & $\mathbf{3 . 9 4 1 6}$ & .66029 \\
\hline Strategic Management & 3.7620 & .53629 \\
\hline
\end{tabular}




\subsection{Hypotheses Testing}

H: Strategic leadership supports functions of strategic management

Table 4. Testing Main Hypothesis

\section{Coefficients}

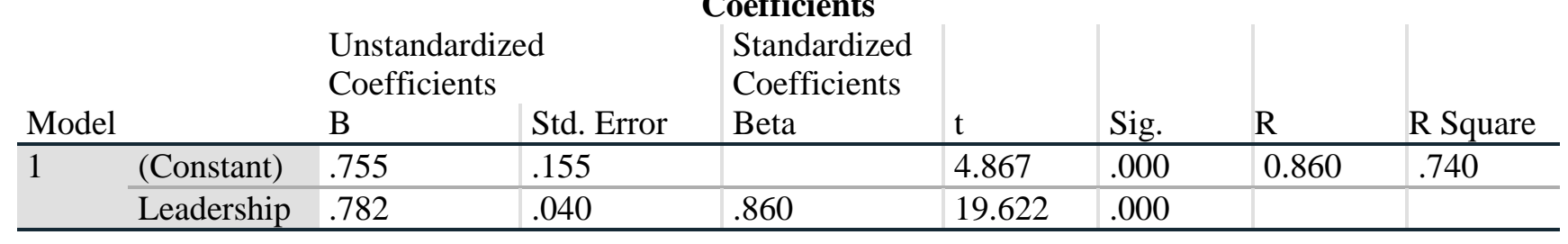

Linear regression was used to test main hypothesis, $\mathrm{t}$ value $=19.622$ was significant at 0.05 level which meant "Strategic leadership supports functions of strategic management". In addition to that $r=0.86$ reflected positive and strong relationship between strategic leadership and strategic management explaining $\mathbf{7 4 \%}$ of the variance in the dependent variable.

Table 5. Testing $1^{\text {st }}$ Sub-Hypothesis

\begin{tabular}{|c|c|c|c|c|c|c|c|c|}
\hline & & & 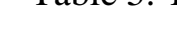 & Coefficients & 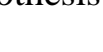 & & & \\
\hline & & Unst & & Standardized & & & & \\
\hline & & Coef & & Coefficients & & & & \\
\hline Model & & $\mathrm{B}$ & Std. Error & Beta & $\mathrm{t}$ & Sig. & $\mathrm{R}$ & R Square \\
\hline 1 & (Constant) & .977 & .444 & & 2.199 & .030 & .428 & .183 \\
\hline & Leadership & .628 & .114 & .428 & 5.496 & .000 & & \\
\hline
\end{tabular}

Linear regression was used to test $1^{\text {st }}$ subhypothesis, $\mathrm{t}$ value $=5.496$ was significant at 0.05 level which meant "Strategic leadership supports planning as a function of strategic management". However, $r=0.428$ reflected positive and medium relationship between strategic management and planning variable explained $\mathbf{1 8 . 3 \%}$ of the variance in the dependent variable.

Table 6. Testing $2^{\text {nd }}$ Sub-Hypothesis

\section{Coefficients}

\begin{tabular}{|c|c|c|c|c|c|c|c|c|}
\hline \multirow[b]{2}{*}{ Model } & & \multicolumn{2}{|c|}{$\begin{array}{l}\text { Unstandardized } \\
\text { Coefficients }\end{array}$} & \multirow{2}{*}{$\begin{array}{l}\text { Standardized } \\
\text { Coefficients } \\
\text { Beta }\end{array}$} & \multirow[b]{2}{*}{$\mathrm{t}$} & \multirow[b]{2}{*}{ Sig. } & \multirow[b]{2}{*}{$\mathrm{R}$} & \multirow[b]{2}{*}{ R Square } \\
\hline & & $\mathrm{B}$ & Std. Error & & & & & \\
\hline 1 & (Constant) & 1.535 & .379 & & 4.045 & .000 & .433 & .188 \\
\hline & Leadership & .544 & .097 & .433 & 5.582 & .000 & & \\
\hline
\end{tabular}

Linear regression was also used to test $2^{\text {nd }}$ subhypothesis, $\mathrm{t}$ value $=5.582$ was significant at 0.05 level which meant Strategic leadership supports organizing as a function of strategic management. In addition to that, $r=0.433$ reflected positive and medium relationship between strategic

\section{Sub-Hypotheses \\ H1: Strategic leadership supports planning as a function of strategic management}

\section{H2: Strategic leadership supports organizing as a function of strategic management}


Table 7. Testing $3^{\text {rd }}$ Sub-Hypothesis

\begin{tabular}{|c|c|c|c|c|c|c|c|c|}
\hline & & & 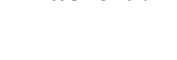 & oefficients & 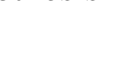 & & & \\
\hline & & Unst: & & $\begin{array}{l}\text { Standardized } \\
\text { Coefficients }\end{array}$ & & & & \\
\hline Model & & B & Std. Error & Beta & $\mathrm{t}$ & Sig. & $\mathrm{R}$ & R Square \\
\hline 1 & (Constant) & .486 & .113 & & 4.288 & .000 & .936 & .876 \\
\hline & Leadership & .898 & .029 & .936 & 30.817 & .000 & & \\
\hline
\end{tabular}

Linear regression was used to test $3^{\text {rd }}$ subhypothesis, $\mathrm{t}$ value $=30.817$ was significant at 0.05 level revealing that Strategic leadership supports staffing as a function of strategic management. Also, $r=0.936$ reflected positive and strong relationship between Strategic leadership and staffing explained $\mathbf{8 7 . 6 \%}$ of the variance in the dependent variable.

H4: Strategic leadership supports leading as a function of strategic management

Table 8. Testing $4^{\text {th }}$ Sub-Hypothesis

\section{Coefficients}

\begin{tabular}{|c|c|c|c|c|c|c|c|c|}
\hline \multirow[b]{2}{*}{ Model } & & \multicolumn{2}{|c|}{$\begin{array}{l}\text { Unstandardized } \\
\text { Coefficients }\end{array}$} & \multirow{2}{*}{$\begin{array}{l}\text { Standardized } \\
\text { Coefficients } \\
\text { Beta }\end{array}$} & \multirow[b]{2}{*}{$\mathrm{t}$} & \multirow[b]{2}{*}{ Sig. } & \multirow[b]{2}{*}{$\mathrm{R}$} & \multirow[b]{2}{*}{ R Square } \\
\hline & & $\mathrm{B}$ & Std. Error & & & & & \\
\hline$\overline{1}$ & (Constant) & .180 & .177 & & 1.017 & .311 & .878 & .771 \\
\hline & Leadership & .970 & .045 & .878 & 21.330 & .000 & & \\
\hline
\end{tabular}

Linear regression was used to test $4^{\text {th }}$ subhypothesis, $\mathrm{t}$ value $=21.33$ was significant at 0.05 level, also, Strategic leadership supports leading as a function of strategic management based on $r=$ 0.878 which reflected positive and strong relationship between Strategic leadership and leading which explained $\mathbf{7 7 . 1 \%}$ of the variance in the dependent variable.

\section{H5: Strategic leadership supports controlling as a function of strategic management}

Table 9. Testing $5^{\text {th }}$ Sub-Hypothesis

\section{Coefficients}

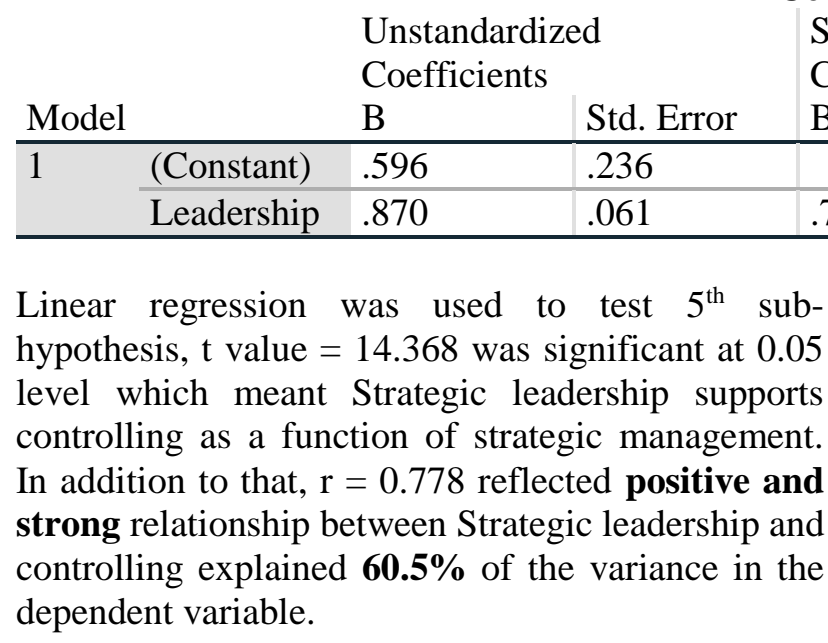

\section{Discussion}

Current research focused on examining how strategic leadership may aid and support functions of strategic management in university environment in Kuwait. For that sake, quantitative approach was utilized and a questionnaire was built and uploaded online for primary data gathering. After application,
Standardized

Coefficients

\begin{tabular}{lllll} 
Beta & $\mathrm{t}$ & Sig. & $\mathrm{R}$ & R Square \\
\hline
\end{tabular}

\begin{tabular}{l|l|l|l|}
778 & 14.368 & .000 & \\
\hline
\end{tabular}

(137) managerial and academic employees responded to the questionnaire and SPSS was used to handle the analysis of primary data. However, study was able to reach following findings:

There appeared to be high awareness among Kuwaiti university managers and academic employees on the importance of leadership in general and strategic leadership in particular

- Employees within Kuwaiti universities believed that the first step towards controlling is to have a good decision making skill which was explained by their leaders

- Level of respondents within Kuwait environment was seen to be high regarding the connection between leadership and management from a strategic perspective 
- Within analysis, it appeared that all subhypotheses were accepted and strategic leadership supports functions of strategic management.

- Among functions of strategic management (planning, organizing, staffing, leading and controlling), there appeared that staffing, leading and controlling were connected to a positive and strong relationship to strategic leadership, however, planning and organizing scored positive and medium relationship to strategic leadership

- The highest function of strategic management in influence appeared to be staffing which explained $87.6 \%$ of the relationship followed by leading which explained $77.1 \%$ of the relationship

- Remaining variables appeared to be influenced with a lower level like controlling $60.5 \%$, organizing $18.8 \%$ and the least was planning $18.3 \%$

Through the above study and results, it can be said that all the hypotheses of the study were accepted with a positive effect between high and medium, that is, strategic leadership has the ability to support strategic management functions specifically in the field of recruitment and selection of competencies, which recorded a high level of impact, followed by leadership with the effect of also high.

The support of strategic leadership has appeared through - at the beginning - the strategic thought calling for attention to resources and studying the competitive environment that exists in the strategic management. It increases the team's ability to achieve the desired goals, especially the distribution of organizational resources and measuring the difficulty of the competitive environment, as confirmed by [1] and [15] in their study.

In addition, the study found that all strategic management functions are affected by strategic leadership, especially in the areas of employment and talent acquisition, as well as leadership in its literal sense, because, as is known administratively, the higher administration is usually responsible for planning and drawing up public policies and a map The road, while leadership is the closest to the working individuals and the most capable of interacting with them, managing them and directing them to the desired path. Therefore, the fact that leadership and polarization - as the functions of strategic management - are among the functions most affected by strategic leadership gives greater legitimacy to the results of the study and confirms them as confirmed by [13].
Results also matched what came along with [14] assuring that strategic leadership and its quality have an active role in the adoption, formation and implementation mechanism of the strategic policies previously adopted by the administration, as the strategic leadership formed in its axis the link between the heart of the organization and its body, it is the link between senior management and individuals working in various organizational structures, which encourages Individuals to be more successful and motivated towards achieving organizational goals derived from the management strategy in general.

In addition, results of study proved that strategic leadership can be considered as an intellectual schism of strategic management, as it carries the same intellectual approach and strategic ideologies based on the importance of studying and analyzing the resources of the organization, and enhancing the mechanism of exploiting them in the optimal way, as well as creating a study and analysis mechanism for competitive environment in a way that guarantees the possibility of continuity and extending the life of the organization in light of an unstable environment filled with various obstacles in terms of the presence of strong competitors, the emergence of new competitors, and continuous technological development that must be followed up and kept up with it constantly. This was also agreed on by [15].

\section{Conclusion and Recommendations}

Strategic leadership is the main and most important player in linking strategic management with the organization's goals and vision, as strategic thinking usually starts from understanding the vision, supporting the organizational culture and realizing the foundations on which the goals will be achieved. Likewise, the prevailing values in the organization usually greatly affect the achievement of the strategic goals of the organization, here the role of leadership appears in modifying and framing these values and forming them in a way that suits the strategic goals by clarifying the adopted values of the organization, clarifying its culture, and manifestations of its vision within coming environment and timeframe.

On the other hand, the strategic management is the one who enacts the policies, legislation and strategies to be adopted, while the strategic leadership is the one who ensures the meeting of the organization's members to achieve these strategies and the participation of everyone in them and to avoid resistance to change in all its forms by 
inspiring and motivating others to move forward towards achieving the required efficiently.

Launching from research results, discussion and conclusion, it was seen that the most important characteristics of strategic leader is challenging preconceived notions and foreseeing the future, so, it is recommended that risk management in all its forms and strategies is the most important fact in this scheme, given that strategic management is mostly based on managing in an unpredictable environment that is unstable and risky.

\section{References:}

[1] Agrawal, Dinesh C. Management: Implementation of Policies and strategies in the planning process. Bhartiyam International Journal of Education \& Reserch, Vol. 1, No.1, 2011, pp. 1-8.

[2] Alkheyi, A. A. S. A., et al. Strategic leadership practices on team effectiveness: the mediating effect of knowledge sharing in the UAE Municipalities. Academic Leadership,, Vol. 21, No.3, 2020, pp. 99-112.

[3] Altman, Elizabeth J., and Michael L. Tushman. Platforms, open/user innovation, and ecosystems: A strategic leadership perspective. Emerald Publishing Limited, 2017.

[4] Angiola, Nunzio, Piervito Bianchi, and Letizia Damato. How to Improve Performance of Public Universities? A Strategic Management Approach. Public Administration Quarterly, Vol. 43, No.3,2019.

[5] Wilkinson, Adrian, Steven J. Armstrong, and Michael Lounsbury, eds. The Oxford handbook of management. Oxford University Press, 2017.

[6] Cole, Rosanna, and Brent Snider. Managing in turbulent times: The impact of sustainability in management education on current and future business leaders. Journal of cleaner production, Vol. 2, No, 10, 2019, pp. 1622-1634.

[7] Dzwigol, Henryk. Methodological and empirical platform of triangulation in strategic management. Academy of Strategic Management Journal, Vol. 19, No.4, 2020, pp. 1-8.

[8] Fuertes, Guillermo, et al. Conceptual framework for the strategic management: a literature review-descriptive. Journal of Engineering, 2020.

[9] Gachugu, Ehud M., et al. Top management team diversity and organizational performance: An empirical investigation of strategic leadership influence, Vol. 5, No. 3, 2019.

[10] Gunasekaran, Angappa, and Ana Beatriz Lopes de Souza Jabbour, eds. Managing organizations for sustainable development in emerging countries. Routledge, 2017.

[11] Hambrick, Donald C., and Adam J. Wowak. Strategic leadership. Strategic Management: State of the Field and Its Future, Vol. 7, No.3, 2021, pp. 337.

[12] Hitt, Michael, and R. Duane Ireland. The intersection of entrepreneurship and strategic management research. The Blackwell handbook of entrepreneurship, Vol. 3, No. 8, 2017, pp. 45-63.

[13] Hunitie, Mohammad. Impact of strategic leadership on strategic competitive advantage through strategic thinking and strategic planning: a bi-meditational research. Verslas: teorija ir praktika, Vol. 19, No.1, 2018, pp. 322-330.

[14] Jabbar, Ali Abdulridha, and Ali Mohammed Hussein. The role of leadership in strategic management. International Journal of Research-Granthaalayah, Vol. 5, No.5, 2017, pp. 99-106.

[15] Kasim, Raja Suzana Raja. The relationship of strategic leadership characteristics, gender issues and the transformational leadership among institutions of higher learning in Malaysia. Academic and Business Research Institute Conference-Las Vegas, 2010 Conference Proceeding. No. 10054. Academic and Business Research Institute, 2010.

[16] Keeton, William. Command, leadership, intelligence and management (CLIM): A proposed theory for improved strategic leadership. FIIB Business Review, Vol.7, No.2, 2018, pp. 146-151.

[17] Koca, S. Development of Strategic Management in Universities. A 43 Журнал включен в Российский индекс научного иитирования, Vol. 6, No.2, 2017

[18] Kurzhals, Christopher, Lorenz Graf-Vlachy, and Andreas König. Strategic leadership and technological innovation: A comprehensive review and research agenda. Corporate Governance: An International Review, Vol. 28, No.6, 2020, pp. 437-464.

[19] M'Mugambi, David Kinyua, Washington Okeyo, and Magdalene Muthoka. The Role of Strategic Leadership Style on Compliance with Public Service Ethics in the County 
Governments of Kenya. Journal of Human Resource \& Leadership, Vol. 5, No.1, 2021, pp. 46-61.

[20] Makadok, Richard, Richard Burton, and Jay Barney. A practical guide for making theory contributions in strategic management. Strategic Management Journal, Vol, 39, No.6, 2018, pp. 1530-1545.

[21] Manuti, Amelia, Maria Antonietta Impedovo, and Pasquale Davide De Palma. Managing social and human capital in organizations: Communities of practices as strategic tools for individual and organizational development. Journal of workplace learning, Vol. 6, No2, 2017.

[22] Nachbagauer, Andreas GM. Beyond Risk Management: Managing the Unexpected. Shift, Vol. 6, No5, 2017, pp. 133146.

[23] Najmaei, Arash. Revisiting the strategic leadership paradigm: A gender inclusive perspective. Inclusive Leadership. Palgrave Macmillan, Cham, 2018. Pp. 203-228.

[24] Olaka, Habil, Peter Lewa, and Peter Kiriri. Strategic leadership and strategy implementation in commercial banks in Kenya, 2017.

[25] Ortmann, Günther, and Jörg Sydow. Creativity in/of Organizations for Managing Things to Come: Lessons to Be Learnt from Philosophy. How Organizations Manage the Future. Palgrave Macmillan, Cham, Vol. 5, No.3, 2018, pp. 67-88.

[26] Parakhina, Valentina, et al. Strategic management in universities as a factor of their global competitiveness. International Journal of Educational Management, Vol. 6, No.3, 2017.

[27] Prasad, L. M. Principles and practice of management. Sultan Chand \& Sons, 2020.

[28] Ramos-Monge, Elva L., X. Llinàs-Audet, and Jesus Barrena-Martinez. Universities as corporate entities: The role of social responsibility in their strategic management. Corporate governance and strategic decision making, Vol. 8, No.1, 2017, pp. 199-215.

[29] Shao, Zhen. Interaction effect of strategic leadership behaviors and organizational culture on IS-Business strategic alignment and Enterprise Systems assimilation. International Journal of Information Management, Vol.4, No.4, 2019, pp. 96-108.

[30] Siegel, Donald S., and Sohvi Leih. "Strategic management theory and universities: An overview of the Special Issue." Strategic Organization, Vol. 16, No.1, 2018, pp. 6-11.

[31] Sułkowski, Łukasz, and Andrzej Woźniak. Strategic management at universities in merger processes: research results, Vol. 9, No.1, 2019.

[32] Velikorossov, V. V., et al. Strategic management. (2020).

[33] Ящук, Тетяна Анатоліївна. Marketing strategic management of universities. Diss. Kiev: NAU, 2019.

\section{Creative Commons Attribution License 4.0 (Attribution 4.0 International, CC BY 4.0)}

This article is published under the terms of the Creative Commons Attribution License 4.0 https://creativecommons.org/licenses/by/4.0/deed.en _US 